\title{
VALORES HUMANOS E SEXISMO AMBIVALENTE
}

\author{
Nilton S. Formiga
}

\begin{abstract}
Resumo
O preconceito, independente do grupo em que se encontre o indivíduo, é um fenômeno antigo. Atualmente, é possivel observar que algumas práticas discriminatórias vêm assumindo novas facetas, não ocorrendo a sua diminuição, mas a apresentação de uma versão sutil. Uma das promissoras explicações deste problema centra-se nos valores humanos, principalmente porque esse construto é capaz de orientar escolhas, atitudes, avaliação comportamental e situações sociais. 200 graduandos, de ambos os sexos, do curso de Psicologia de uma Universidade privada responderam coletivamente nas salas de aula o inventário de sexismo ambivalente, valores humanos e dados sócio-demográficos. Observouse que o critério de orientação valorativa pessoal relacionou-se com o sexismo hostil e benévolo, já o social apenas com o benévolo. Os valores que visam um individualismo foram capazes de fomentar tanto o preconceito sutil quanto tradicional, e que os que apontam para uma orientação social, salientou também uma discriminação sutil.
\end{abstract}

Palavras-chave: Valores Humanos; Sexismo Ambivalente; Preconceito.

\section{Human VAluES AND AMBIVALENT SEXISM}

\begin{abstract}
The Prejudice, independent of the group to which the individual belongs, is a very old phenomenon. Presently it is possible to observe that some discriminatory practices are assuming new faces. Rather than diminishing prejudice, they present subtle, camouflaged versions. One promising explanation of this problem is centered in human values, because this construct is capable of orientating choices, attitudes, value judgments, and social situations. 200 students of both sexes graduating from the Psychology course of a private university answered the inventory of sexual ambivalence, basic human values and socio-demographic data was collectively given in the classroom. It was observed that personal value orientation related to hostile and benevolent sexism, while social value orientation
\end{abstract}

\footnotetext{
^ $\mathrm{O}$ autor é mestre em psicologia social pela universidade Federal da Paraíba. Atualmente, é professor na mesma universidade e coordenador do grupo de pesquisa comportamento social e valore humanos. Durante a realização deste estudo o autor contou com Bolsa de Produtividade do $\mathrm{CNPq}$, instituição a qual agradece. Endereço: Avenida: Guarabira, 133. Bairro de Manaíra. Cep: 58038-140. João Pessoa - PB. Brasil.

E-mail:nsformiga@yahoo.com
} 
related only to benevolent sexism. Thus, values which favor individualism were capable of fomenting a subtle prejudice as well as traditional prejudice, which points to the significance of social orientation and subtle discrimination.

Keywords: Human values; Ambivalent sexism; Prejudice.

\section{INTRODUÇÃO}

O tema sobre o preconceito ainda sugere muitos estudos, principalmente, no que diz respeito à explicação da estabilidade desse fenômeno nas relações interpessoais. Essa condição tem promovido diversas perspectivas teóricas, da psicanalítica, sociológica, sócio-cognitiva a psicossocial (KLINENBERG, 1974; FISKE, 1989; AMÂNCIO, 1994; MUNNÉ, 1996; FONSECA, 2000; RODRIGUES, 2001), tem procurado contribuir na compreensão da manifestação do preconceito, justamente por perceber-se que as pessoas já não são tão estáticas, mas, cognitiva e socialmente, dinâmicas; isto leva-nos a pensar que o processo de construção da realidade social do preconceito flutua, justamente, na interação social, permitindo discutir sobre a dinâmica e origem das atitudes preconceituosas.

Mesmo com tantos enfoques e investidas sócio-humanas na busca de inibir ou diminuir a desigualdade social, principalmente, em relação às formas de discriminação frente aos diversos grupos sociais (FORMIGA et al., 2004; OLIVEIRA et al., 1998) e a manutenção do bem-estar social e psicológico das pessoas que sofrem com esse problema, parece que, concretamente, nao se tem mostrado uma diminuição significativa quanto à manifestação social do preconceito, ao contrário, ele vem se apresentando sob uma versão sutil, camuflada, etc. (FORMIGA, 2004; PETTIGREW; MEERTENS, 1995; SWIM et al., 1995; TOUGAS et al., 1995; TORRES, 1998). Tal fato, salienta uma dicotomia entre o pensar e fazer do sujeito em relação a concordância ou não da expressão aberta do preconceito (MONTE; FORMIGA, 2000), apresentando uma manutenção discreta na qual alude a desejabilidade social (TORRES, 1998) das atitudes preconceituosas, o que leva a crer na sutiliza desse fenômeno (MONTE, 2001) refletindo em termos da não existência do preconceito ou o seu contínuo desaparecimento (CAMINO; SILVA; MACHADO, 2003).

Considerando tais questões, parece não haver diferença em relação a manifestação do preconceito, independente de qual categoria social a pessoa possa pertencer (ser negro, homossexual, estrangeiros ou mulheres); ele existe de fato, e esse problema é percebido a partir do delineamento dos limites de poderes entre grupos sociais minoritários vs majoritários (BREWER, 1999). O que é possível acompanhar é o pulular de práticas discriminatórias "politicamente corretas" (TOUGAS et al., 1995) que contribuem em direção especulativa do preconceito nas Ciências Humanas e Sociais (AGUIAR, 1997) e por que este ainda permanece na sociedade, principalmente em relação às mulheres. Sendo assim, as causas e conseqüências podem ser vislumbradas e até defendidas, porém, conhecer a extensão concreta desse fato, faz-se necessário considerar diretamente os agentes que o incitam: homens e mulheres da sociedade civil e suas opiniões, atitudes e 
pensamentos sobre o papel da mulher em diferentes facetas da sociedade, tornando-se crucial no momento de compreender as formas e conteúdos do preconceito (FORMIGA; GOUVEIA; SANTOS, 2002).

De fato, a discriminação feminina tem atingindo diversos campos da sociedade mundial: a educação, o trabalho, a política e a ciência. Tais espaços têm pretendido tornar mais transparente a forma de organização, de luta igualitária e dos direitos humanos, integrando as estruturas patriarcais do capitalismo a uma nova visão desenvolvimentista e histórica que discute a dominação do gênero e sua inter-relação com as classes, a etnicidade, a sexualidade etc. (CRENSHAW, 2002; FIÚZA, 2001; PRINGLE, 1997). Essas perspectivas visam contribuir em direção da compreensão da construção do gênero como prática "imposta" socialmente, consecutivamente, levando a crer na debilidade e inferioridade das mulheres quando comparadas com os homens (FIÚZA, 2001). No presente trabalho pretende-se aproximar às pesquisas que compreendem o "sexismo" como um conjunto de estereótipos sobre a avaliação cognitiva, afetiva e atitudinal acerca do papel apropriado na sociedade dirigida aos indivíduos de acordo com o sexo (EXPÓSITO; MOYA; GLICK, 1996; GLICK; FISKE, 1996; MYERS, 1999).

Esse construto, proposto por Glick e Fiske (1996), enfatiza a existência de novas formas de sexismo consideradas ambivalentes, justamente por estas não serem tão diretas quando se considera a prática e expressão discriminatória tradicional, as quais estão baseadas na inferioridade ou diferença das mulheres como um grupo minoritário e meritrocrático para a condição social em que vivem. Isto não se trata apenas da definição tradicional de preconceito como antipatia ou hostilidade em direção aos membros de certos grupos sociais, refletido na obra de Allport (1954), a qual impede apreender a verdadeira essência desse construto (MLADINIC et al., 1998) diferenciando de outras formas de intolerância social (por exemplo, racial, religiosa, econômica) deflagrando que o preconceito em relação à mulher não é uniformemente negativo, mas permeadores de atitudes e comportamentos positivos também, daí a hipótese de que esse fenômeno se manifesta na forma ambivalente (FORMIGA et al., 2004).

O sexismo ambivalente é apresentado em duas formas principais: "hostil" e "benévolo". O "primeiro" é uma expressão mais flagrante de preconceito em relação às mulheres, aproximando-se da definição clássica deste atributo psicossocial (ALLPORT, 1954). Este tem sido extensamente tratado (GLICK; FISKE, 1996), porém não permite compreender totalmente a direção que toma o sexismo na sociedade atual, justificando a luz da busca de igualdade em direitos e deveres entre os gêneros (SIANO, 2000), evidenciando crenças e práticas típicas de pessoas que consideram as mulheres inferiores aos homens, bem como, refletindo antipatia e intolerância em relação ao seu papel como figura de poder e decisão. O "segundo" se constitui a partir das concessões e tratamentos diferenciados entre homens e mulheres, referindo-se a uma atitude positiva, aparentemente não preconceituosa em relação à mulher, porém descrevendo-a como pessoa frágil, necessitando de atenção e etc. 
Mesmo com a "valorização" da mulher é possível subentender o papel social que a ela é atribuído: ser mãe e responsável a fim de prover o afeto na família, cuidar dos filhos, do esposo, etc.; define-se uma identidade em termos de sua dependência ou co-dependência, fragilidade e sensibilidade. Tal sexismo embora contemple de maneira estereotipada e desempenhe papéis restritivos a elas, possui para quem o manifesta um tom subjetivamente positivo fomentando o estímulo de comportamentos pró-sociais ou promotores de intimidade (MLADINIC et. al., 1998; FORMIGA; GOUVEIA; SANTOS, 2002). Apesar de ser proibido por lei, o sexismo existe de fato, em maior ou menor medida, em todas as partes do mundo, deixando de ser uma forma aberta de discriminação contra a mulher, assumindo contornos sutis, o que leva a crer que não existe nenhuma dúvida quanto a sua extensão na sociedade civil.

Porém, ao se refletir sobre as explicações teóricas e empíricas que tratam da discriminação de um modo geral no mundo, uma das preocupações principais é quanto as variáveis que possam explicar esse fenômeno. A perspectiva teórica dos valores humanos tem trazido grandes frutos quanto à explicação dos fenômenos sociais, sendo o preconceito um deles. Esse construto tem sido considerado de grande importância na explicação dos comportamentos das pessoas, justamente, por serem capazes de orientar escolhas, atitudes e avaliação dos comportamentos e das situações sociais, bem como, hierarquiza-las a partir da importância relativa que cada um atribui (ROKEACH, 1973, 1979; SCHWARTZ; BILSKY, 1987; GOUVEIA, 1998) nas relações sociais. Tal construto visa à diferenciação entre o que é importante e secundário para o indivíduo, pois são capazes de revelar tanto a relação com o comportamento e as opções de vida dos indivíduos quanto a sua preferência no que diz respeito ao que tem ou não valor (TAMAYO, 1988), além do mais, os valores expressam um forte componente de desejabilidade social, através do qual as pessoas se apresentam na sociedade se importando com a justificativa de seus comportamentos e atitudes diante dos outros (GOUVEIA; QUEIROGA, 2001).

Vale destacar que quando se fala que uma pessoa tem valores, salienta-se uma "crença duradoura", isto é, uma maneira de se comportar ou um estado final de existência da mesma, os quais podem ser preferidos, tanto no âmbito pessoal quanto social (GUSMÃO et al., 2001). Ao considerar as novas perspectivas teóricas sobre preconceito, a qual defende que este fenômeno se manifesta ambivalente, nas formas sutil ou mascarada, pode-se refletir que este problema frente aos grupos minoritários não somente podem está relacionado a valores individualistas, os quais priorizam o êxito, sucesso pessoal e independência, mas também, a valores sociais, os quais dizem respeito as pessoas que valoram a tradição, o próprio grupo, harmonia na relação e uma interdependência; isto é, parece que não poder escapar desse problema, seja através de uma orientação individualista ou coletivista, o preconceito aparecerá, explicita ou implicitamente.

Sendo assim, concebe-se que os valores humanos se estruturam no sistema psicológico, promovendo coerentemente a ação humana (ROKEACH, 1973), podendo tratá-los, metaforicamente, como um "termômetro" social, capaz de indicar o estado febril da sociedade, evitando assim certas convulsões (FORMIGA; QUEI- 
ROGA; GOUVEIA, 2001). Por este construto ser capaz de orientar comportamentos e atitudes das pessoas frente aos fenômenos sociais é bem possível que ele possa explicar tanto a forma sutil quanto tradicional do preconceito frente as mulheres. Porém, devido à diversidade de modelos teóricos sobre valores que podem ser encontradas nas ciências humana e social, pretende-se enfatizar uma tipologia alternativa a partir da consideração da relação existente entre valores e necessidades humanas (ROKEACH, 1973; INGLEHART, 1991; SCHWARTZ, 1992).

Esta é uma extensão das teorias sobre valores já existentes, concebendo-os como categorias de orientação que são desejáveis, baseadas nas necessidades humanas e nas pré-condições para satisfazê-las, sendo adotadas por atores sociais. Tais valores apresentam diferentes magnitudes e seus elementos constitutivos podem variar a partir do contexto social ou cultural em que a pessoa está inserida (GOUVEIA, 1998; p. 293). Este modelo apresenta 24 valores, distribuídos em seis funções psicossociais: existência, experimentação, realização, normativo, interacional e suprapessoal, as quais, por sua vez, se reúnem em três critérios de orientação valorativa: pessoal, social e central. Desta maneira, a partir do critério valorativo assumido pelos sujeitos as atitudes preconceituosas poderão ser explicadas seja considerando uma orientação que enfatize o próprio sujeito ou o seu grupo, já que ter valores não apenas diz respeito a apreendê-lo subjetivamente, mas, além de quere ter um valor é necessário condição para que este exista e possa fazer parte do universo social e cognitivo do ser humano.

O presente estudo compreende um delineamento de tipo correlacional, considerou-se como variável antecedente: os "valores humanos"; e as variáveis critérios, o "sexismo ambivalente hostil e benévolo".

\title{
Metodologia
}

\begin{abstract}
Amostra
Participaram da pesquisa 200 estudantes universitários de ambos os gêneros, do Centro Universitário de João Pessoa. A maioria dos quais mulheres (85\%), com idade variando de 20 a 56 anos $(\mathrm{M}=25,10 ; \mathrm{DP}=7,80)$. Esta amostra é não probabilística, podendo ser definida como intencional. Foram consideradas as pessoas que, ao serem consultadas, dispusera-se a colaborar respondendo o questionário que era apresentado.

Instrumentos

Os participantes responderam os seguintes questionários:

Inventário de Sexismo Ambivalente - ISA. Elaborado originalmente em língua inglesa (GLICK; FISKE, 1996), o instrumento é composto por 22 itens que avaliam os estereótipos assumidos por cada gênero a respeito de duas dimensões do sexismo: hostil (por exemplo, As mulheres feministas estão fazendo exigências completamente sem sentido aos homens; A maioria das mulheres não aprecia completamente tudo o que os homens fazem por elas) e benévolo (por exemplo, As mulheres devem ser queridas e protegidas pelos homens; Muitas
\end{abstract}


mulheres se caracterizam por uma pureza que poucos homens possuem). Para respondê-lo a pessoa deveria ler cada item e indicar o quanto está de acordo com o conteúdo expresso, para isso, numa escala de quatro pontos, tipo Likert, com os seguintes extremos $\mathbf{1}=$ Discordo Totalmente e $\mathbf{4}=$ Concordo Totalmente ele deveria indicar a resposta. Esta versão foi traduzida ao português por um psicólogo bilíngüe e avaliada por um outro da mesma categoria que a comparou com uma versão espanhola (EXPÓSITO; MOYA; GLICK, 1998) e validada por Formiga, Gouveia e Santos (2002), os quais encontraram parâmetros psicométricos $\left(\mathrm{GFI}=0,77\right.$ e $\left.\mathrm{AGFI}=0,72 ; \chi^{2} / \mathrm{g} .1 .=3,18 ; \mathrm{RMSR}=0,10\right)$ aceitáveis no inventário para a população brasileira.

Questionário dos Valores Básicos - QVB. Uma versão inicial foi proposta em espanhol e português, compreendendo então 66 itens, três por cada um dos valores básicos que avaliava (GOUVEIA, 1998). Utilizou-se uma versão modificada, cuja comprovação, a partir de uma análise fatorial confirmatória, apresentou parâmetros psicométricos aceitáveis na população estudada, tendo os seguintes indicadores de bondade de ajuste: $\chi^{2} / \mathrm{gl}=3,02, \mathrm{GFI}=0,91, \mathrm{AGFI}=0,89$ e RMSR $=0,07$ (MAIA, 2000). Formado por 24 itens-valores, com etiquetas que ajudam a entender o seu conteúdo (por exemplo, Tradição - seguir as normas sociais do seu país; respeitar as tradições da sua sociedade; Êxito - obter o que se propõe; ser eficiente em tudo que faz; Justiça Social - lutar por menor diferença entre pobres e ricos; permitir que cada indivíduo seja tratado como alguém valioso); para respondê-los, a pessoa deveria avaliar o seu grau de importância como um princípio-guia na sua vida e indicar sua resposta numa escala de sete pontos, com extremos 1 = Nada Importante a $7=$ Muito Importante. No final precisava indicar o valor menos e o mais importante de todos, os quais receberiam pontuações 0 e 8 , respectivamente.

Caracterização Sócio-Demográfica - Uma folha separada foi anexada ao instrumento prévio, onde eram solicitadas informações de caráter sócio-demográfico (por exemplo, idade, sexo, estado civil, etc.).

\section{Procedimento}

Procurou-se definir um mesmo procedimento padrão que consistia em aplicar tanto o ISA (Inventário de Sexismo Ambivalente) quanto QVB (Questionário de Valore Básicos) coletivamente em sala de aula. Um único pesquisador ficou responsável pela coleta dos dados; após conseguir a autorização da coordenação dos cursos e professor responsável pela disciplina, este se apresentava em sala de aula como interessado em conhecer as opiniões e os comportamentos das pessoas no dia a dia, solicitando a colaboração voluntária dos estudantes no sentido de responderem um questionário breve. Foi-lhes dito que não havia respostas certas ou erradas, e que respondessem individualmente; a todos era assegurado o anonimato das suas respostas, que seriam tratadas em seu conjunto. Apesar de o questionário ser auto-aplicável, contando com as instruções necessárias para que possa ser respondido, o pesquisador esteve presente durante toda a aplicação para retirar eventuais dúvidas ou realizar es- 
clarecimentos que se fizessem indispensáveis. Um tempo médio de 15 minutos foram suficientes para concluir essa atividade.

\section{Tabulação e Análise dos Dados}

O pacote estatístico SPSSWIN, em sua versão 11.0, foi utilizado para tabular os dados e realizar as análises estatísticas descritivas, bem como os cálculos referentes ao coeficiente de correlação $r$ de Pearson.

\section{Resultados E Discussao}

Tendo como objetivo principal no presente estudo avaliar a relação entre valores humanos básicos e o sexismo ambivalente, hostil e benévolo, procedeuse uma correlação de Pearson (r) entre essas variáveis. Inicialmente, avaliou os escores correlacionais entre as dimensões do sexismo ambivalente, observando uma relação direta e significativa, entre o sexismo benévolo e hostil ( $\mathrm{r}=0,22 ; \mathrm{p}$ $<0,01)$. Em seguida, tanto para os critérios de orientação valorativa quanto às funções psicossociais dos valores, foi realizado o mesmo calculo.

Na tabela 1, observou-se uma correlação direta entre os tipos de Sexismo Tabela 1. Correlações entre as Funções Psicossociais dos Valores e o Sexismo Ambivalente.

\begin{tabular}{lcc} 
& \multicolumn{2}{c}{ SEXIMOS AMBIVALENTE } \\
\cline { 2 - 3 } FUNÇÕES PSICOSSOCIAIS & Hostil & Benévolo \\
DOS VALORES HUMANOS & & $\mathbf{0 , 1 9 * *}$ \\
Experimentação & $\mathbf{0 , 1 8 *}$ & $\mathbf{0 , 1 5 *}$ \\
Realização & $\mathbf{0 , 2 1 * * *}$ & 0,12 \\
Existência & 0,08 & $-0,01$ \\
Supra-Pessoais & $-0,01$ & $\mathbf{0 , 1 4 *}$ \\
Interacionais & 0,03 & $\mathbf{0 , 2 8 * * *}$ \\
Normativa & 0,12 &
\end{tabular}

Notas: ${ }^{*} \mathrm{p}<0,05,{ }^{*} \mathrm{p}<0,01, * * * \mathrm{p}<0,001$ (teste unilateral; eliminação pairwise de casos em branco).

Benévolo e as seguintes funções psicossociais valorativas de Experimentação ( $\mathrm{r}$ $=0,19 ; \mathrm{p}<0,05)$, Realização $(\mathrm{r}=0,15 ; \mathrm{p}<0,05)$, Normativa $(\mathrm{r}=0,29 ; \mathrm{p}<0,05)$ e Interacional $(\mathrm{r}=0,14 ; \mathrm{p}<0,05)$. No que diz respeito ao Sexismo Hostil, apenas Experimentação $(\mathrm{r}=0,18 ; \mathrm{p}<0,05)$ e Realização $(\mathrm{r}=0,21 ; \mathrm{p}<0,05)$ se relacionaram com essa dimensão mais tradicional do sexismo (ver tabela 1). De acordo com o sugerido anteriormente, considerando os critérios de orientação cultural e os tipos de sexismos, foram encontrados os seguintes resultados: o sexismo benévolo relacionou-se apenas com o critério social $(\mathrm{r}=0,23 ; \mathrm{p}<0,001)$. Já quanto ao sexismo hostil observou-se que apenas tanto o critério valorativo pessoal ( $\mathrm{r}$ $=0,21 ; \mathrm{p}<0,001)$ e social $(\mathrm{r}=0,23 ; \mathrm{p}<0,001)$ correlacionaram-se com estas dimensões do preconceito; vale destacar que para o sexismo hostil e benévolo o critério central não apresentou relação significativa (ver tabela 2). 
Tabela 2. Correlações entre as Orientações Valorativas e o Sexismo Ambivalente.

\begin{tabular}{lcc} 
& \multicolumn{2}{c}{ SEXIMOS AMBIVALENTE } \\
\cline { 2 - 3 } ORIENTAÇÕES & Hostil & Benévolo \\
VALORATIVAS & & \\
& $\mathbf{0 , 2 1 *}$ & $\mathbf{0 , 2 0 *}$ \\
Pessoal & 0,09 & $\mathbf{0 , 2 3}$ \\
Social & $-0,01$ & $-0,01$ \\
Central & & \\
\hline
\end{tabular}

Notas: $* \mathrm{p}<0,001$ (teste unilateral; eliminação pairwise de casos em branco).

Essas considerações a respeito dos valores humanos, principalmente, em se tratando da teoria proposta - valores humanos básicos (GOUVEIA, 1998) composta de 24 valores básicos e que expressam princípios-guia, dando origem a um sistema de valor o qual apresenta critérios de orientação (pessoal, social e central) e as funções psicossociais (experimentação, realização, existência, suprapessoal, interacional e normativo) como já enfatizado, resolveu-se como um dado adicional relacionar os tipos de sexismo com os 24 valores a fim de avaliar o quanto a relação com esses valores seriam consistentes individualmente, os resultados foram os seguintes: em relação ao sexismo hostil foram encontradas correlações negativas com justiça social $(\mathrm{r}=-0,20 ; \mathrm{p}<0,001)$, sabedoria $(\mathrm{r}=$ - 0,13; $\mathrm{p}<0,01)$, prestígio $(\mathrm{r}=-0,16 ; \mathrm{p}<0,001)$ e autodireção $(\mathrm{r}=-0,17 ; \mathrm{p}<$ $0,001)$; já tradição $(r=0,17 ; \mathrm{p}<0,001)$ e emoção $(\mathrm{r}=0,16 ; \mathrm{p}<0,05)$ relacionouse diretamente. Quanto ao sexismo benévolo, observou-se uma relação negativa com os valores maturidade $(r=-0,13 ; \mathrm{p}<0,05)$ e obediência $(\mathrm{r}=-0,17 ; \mathrm{p}<0,01)$; porém emoção $(r=0,19 ; \mathrm{p}<0,001)$, êxito $(\mathrm{r}=0,14 ; \mathrm{p}<0,05)$, poder $(\mathrm{r}=0,13 ; \mathrm{p}<$ $0,05)$ e prestígio $(\mathrm{r}=0,21 ; \mathrm{p}<0,01)$ se relacionaram diretamente com o sexismo benévolo (ver tabela 3 ).

No presente estudo procurou-se relacionar os valores humanos e o sexismo ambivalente, visando explicar as causas do preconceito em relação à mulher. Assim, a partir dos resultados obtidos neste trabalho, é preciso considerar que os valores, mostraram o quanto não somente o que visa um individualismo, como é o caso dos valores "experimentação" (o qual enfatiza a descoberta e apreciação de estímulos novos, enfrentamento de situações arriscadas, etc.) e "realização" (visando o autocumprimento, sentimento de ser importante e poderoso, ser uma pessoa com identidade e espaço próprios), mas, aqueles valores que buscam a estabilidade do grupo e o respeito para com os símbolos e padrões culturais, bem como, os que focalizam o destino comum e a complacência, o interesse em ser amada e ter uma amizade verdadeira, e apreciar uma vida social ativa - neste caso, seriam, respectivamente, os valores "normativo" e "interacional" - seriam capazes de influenciar o preconceito, tanto o hostil e quanto o benévolo, em relação à mulher; tais resultados corroboram os achados por Gouveia, Silva e Belo (2003), os quais se assemelham aos desse estudo.

É possível refletir em relação a orientação valorativa e o sexismo; esta relação comprovou que o sujeito orientado por um conjunto de valores capazes de manter as relações pessoais contratuais, procurando obter vantagens / 
Tabela 3: Correlação dos valores humanos básicos e sexismo ambivalente.

\begin{tabular}{|c|c|c|}
\hline \multirow[b]{2}{*}{ VALORES HUMANOS } & \multicolumn{2}{|c|}{ SEXISMO AMBIVALENTE } \\
\hline & Hostil & Benévolo \\
\hline Justiça Social & $-0,20^{* *}$ & $-0,07$ \\
\hline Sabedoria & $-0,13 *$ & 0,03 \\
\hline Beleza & 0,04 & $-0,09$ \\
\hline Maturidade & $-0,04$ & $-0,13^{*}$ \\
\hline Religiosidade & $0,12^{*}$ & 0,01 \\
\hline Ordem Social & $-0,03$ & $-0,05$ \\
\hline Tradição & $0,17 * *$ & $-0,10$ \\
\hline Obediência & $0,12^{*}$ & $-0,17^{* *}$ \\
\hline Afetividade & $-0,10$ & $-0,04$ \\
\hline Apoio Social & 0,05 & $-0,07$ \\
\hline Convivência & $-0,03$ & $-0,03$ \\
\hline Honestidade & $-0,09$ & $-0,01$ \\
\hline Sobrevivência & $-0,01$ & 0,06 \\
\hline Saúde & $-0,08$ & $-0,12$ \\
\hline Estabilidade Pessoal & 0,04 & 0,04 \\
\hline Estimulação & 0,02 & 0,04 \\
\hline Emoção & $0,16^{*}$ & $0,19 * *$ \\
\hline Sexual & $-0,09$ & $-0,04$ \\
\hline Prazer & $-0,01$ & $-0,06$ \\
\hline Êxito & $-0,03$ & $0,14^{*}$ \\
\hline Poder & $-0,05$ & $0,13 *$ \\
\hline Prestígio & $-0,16^{* *}$ & $0,21 * *$ \\
\hline Autodireção & $-0,17^{*}$ & 0,09 \\
\hline Privacidade & 0,08 & $-0,06$ \\
\hline
\end{tabular}

Nota: $* \mathrm{p}<0,05 ; * * \mathrm{p}<0,01 ; * * * \mathrm{p}<0,001$

lucros, bem como, priorizar seus próprios interesses e sua intrapessoalidade (ROKEACH, 1973; SCHWARTZ, 1994), não somente, poderá apresentar um sexismo hostil, mas também, o benévolo. A pessoa tanto discrimina a partir de uma atitude positiva, aparentemente não preconceituosa em relação à mulher quanto pela uma expressão direta do preconceito feminino (FORMIGA et al., 2004). Dessa forma, considerando a orientação social, as pessoas direcionadas para estarem com os outros, focalizando a interpessoalidade e o interesse coletivo (ROKEACH, 1973; SCHWARTZ, 1994) podem contribuir para sua manutenção dessas atitudes, especialmente, para sua forma discreta e sutil, como encontrado nos resultados apresentados na tabela 2; afinal, o preconceito não ocorre no vazio, mas, nas relações sociais e esse fato se deve por se tratar esse fenômeno 
com um simples humor (achincalho, piadas, brincadeiras etc.) às vezes áspero, mas, visto nas relações como nada ofensivo passando, despercebidamente, como uma forma preconceituosa concreta.

Ao observarmos a tabela 3 , tomando os valores isoladamente, pode-se perceber que os valores tradição, religiosidade e obediência foram capazes de explicar diretamente o sexismo hostil; valores estes que aponta para o seguimento de padrões morais seculares, favorecendo um mínimo de harmonia no âmbito social. Por outro lado, o sexismo benévolo, vem ser explicado por valores, positivamente relacionado, como: poder, prestígio, êxito; e outros, com relação negativa, por exemplo, maturidade e obediência. Assim, ao considerar esses valores eles podem revelar uma relação com ambos os sexismos; porém, parece ser melhor compreensivo quando se trata da função psicossocial e critério valorativo das pessoas, primeiro por se contemplar um modelo teórico e segundo por conceber um conjunto de valores, que comparado a outros modelos tem clara vantagem de partir de uma proposta teórica concreta, podendo ser esse conjunto, potencialmente, uma representação das necessidades consensualmente universais (RONEN, 1994). Contar com pontuações compostas, referentes às funções valorativas psicossociais, pode ser uma vantagem adicional, permitindo formular hipóteses de âmbito mais generalizado, aumentando o poder correlaciono e até preditivo do modelo.

Com esse estudo reflete-se em direção das perspectivas proposta por Lima (2003b) a respeito do preconceito quanto a sua avaliação em relação ao negro. Para esse autor, em termos da percepção social, os negros exitosos são percebidos mais com características dos brancos do que negros; os valores normativos do grupo que ascendeu socialmente correspondem, a busca da estabilidade do grupo e o respeito para com os símbolos e padrões culturais vigente. Assim considerado, os negros só conseguiram sucesso porque corresponderam as normas exigidas dos brancos (LIMA, 2003a), isto é, tornaram-se semelhantes em atitudes e valores ao grupo majoritário.

Da mesma maneira, pensar em relação à mulher, é considerar que a discriminação atende aos objetivos implícitos da sociedade, no que diz respeito à mudança e êxito da mulher, se e somente se, atenderem as expectativas propostas pela sociedade (FIÚZA, 2001), tangenciando com isso as formas abertas desse fenômeno, sendo capaz de filtrar suas condições mais diretas, relacionado a um processo mais depurado do preconceito (CAMINO; SILVA; MACHADO, 2003) e a construção de normas sociais concordantes na interação social. O sujeito que possui uma visão conservadora de mundo tenderá as atitudes preconceituosas mais consistentes (FERNANDES et al., 2003; VASCONCELOS, 2001); mas isto, também, não quer dizer que uma abertura da mente, flexibilidade atitudinal e respeito às diferenças mostrem a diminuição do fenômeno, talvez possa revelar uma forma sutil e encoberta, promovendo assim essa ambivalência destacada por Glick e Fiske (1996). 
Esses resultados direcionam-se aos encontrado por Gómez e Huici (1999) em relação às diferenças e hierarquia valorativa de grupos a partir da percepção do exogrupo; eles encontraram justificativas em termos de que os membros da minoria violam os valores da maioria, bem como, diferença na hierarquia dos valores dos membros de cada grupo, por exemplo, enquanto o grupo minoria prioriza o valor universalismo, o majoritário prioriza valor tradição. Parece ser que os grupos minoritários enfatizam uma igualdade de crenças e valores universais, mesmo em situações de competição projetam que todos têm condições para o êxito, sucesso semelhante aos do grupo majoritário, talvez o esforço dispensado para conseguir as coisas não tem sido maior do que o outro grupo.

De fato, a sociedade está impregnada de ideologias capazes de guiarem e justificarem as condutas do indivíduo, fazendo com que elas sejam "comuns" e embasem as práticas para homens e mulheres, os quais adotam esquemas psicológicos e ideológicos que refletem comportamentos a respeito da formação discriminatória de papéis sexuais (PAÉZ; TORRES; ECHEBARRÍA, 1990), principalmente, quanto a sua sutil estabilidade preconceituosa. A aparição do sexismo, tanto benévolo quanto hostil, é sem dúvida um problema no âmbito da pretendida relação de igualdade e de justiça social e de sua manifestação evidente. Camufla-se a discriminação contra a mulher ao tratá-la como um ser especial, frágil e que necessita de cuidados; neste sentido, observa-se a influência dos valores sobre o sexismo, revelando sim, a diminuição da rejeição, porém não a deixando liberta do poder e da dominação do homem (FORMIGA; GOUVEIA; SANTOS, 2002) e sua manifestação de uma base normativa preconceituosa.

Tendo assim a influência valores e sexismo sido comprovada, seria de extrema utilidade programas que enfatizassem uma redução no nível de preconceito entre as pessoas, não somente na sua expressão direta, mas, na busca de inibir a ativação automática do estereótipo (DEVINE, 1989; LIMA; VALA, 2004), já que se considera que o surgimento do preconceito ocorreria a partir dos estereótipos, o qual se alicerça, também, no sistema psicológico, juntamente com os valores (ROKEACH, 1973), que por sua vez orienta nossas escolhas e condutas, possibilitando a existência de uma lógica explicativa: valores-estereótipos-preconceito. Por fim, considera-se que a diferença sexual entre homens e mulheres nos últimos anos vem se tornando mais saliente devido aos valores que os regem, principalmente, por ser este em sua natureza, mais duradoura e universal (ROKEACH, 1973; FRAISSE, 1991), sendo com isso, capaz de modificá-los a partir da intervenção nas atitudes e comportamentos sexistas, a partir dos valores humanos. Apresentadas provas sobre a relação significativa entre valores humanos e sexismo ambivalente, espera-se que os objetivos do estudo tenham sido cumpridos; observou-se que tanto os valores que apontam para uma orientação pessoal quanto social, podem explicar o preconceito frente às mulheres, pois não somente o sujeito que visa os próprios interesses, mas também, o que se preocupa com as tradições contribui para a manutenção desse fenômeno levando-nos a pensar que de fato a discriminação frente a mulheres não somente estão sendo regidas camufladamente, mas, que estão organizadas sobre os valores humanos. 
Nilton S. Formiga

\section{REFERENCIAS}

AGUIAR, N. Gênero e ciências humanas: desafio às ciências desde a perspectiva das mulheres. Rio de Janeiro: Rosa dos Tempos, 1997.

ALLPORT, G. W. The nature prejudice. Reading, MA: Adison-Wesley Publishing Company, 1954.

AMÂNCIO, L. Masculino e feminino: a construção social da diferença. Porto: Afrontamento, 1994.

BREWER, M. B. The psychology of prejudice: ingroup love or outgroup hate? Journal of Social Issues, v. 55, n. 3, p. 429-444, 1999.

CAMINO, L.; SILVA, P.; MACHADO, A. O. Novas formas de preconceito racial: racismo sutil ou mascarado. In: CONGRESSO NORTE-NORDESTE DE PSICOLOGIA: Construindo a Psicologia Brasileira: desafios da ciência e prática psicológica, 3., 2003. Anais... João Pessoa: UFPB, 2003. p. 236.

CRENSHAW, K. Documento para o encontro de especialistas em aspectos da discriminação racial relativos ao gênero. Estudos Feministas, Florianopolis, v. 10, n. 1, p. 171-188, 2002.

DEVINE, D. G. Stereotypes and prejudice: their automatic and controlled components. Journal of Personality and Social Psychology, Washington, v. 56, n. 1, p. 1-18, 1989.

EXPÓSITO, F.; MOYA, M. C.; GLICK, P. Sexismo ambivalente: medición y correlatos. Revista de Psicologia Social, São Paulo, v. 13, p. 159-169, 1998.

FERNANDES, S. et al. Sistemas de valores e orientação à dominância social. In: CONGRESSO NORTE-NORDESTE DE PSICOLOGIA: Construindo a Psicologia Brasileira: desafios da ciência e prática psicológica, 3., 2003. Anais... João Pessoa: UFPB, 2003. p. 258.

FISKE, S. T. Examining the role of intent: toward understanding its role in stereotyping and prejudice. In: ULEMAN, S. J.; BARGH J. A. (Org.). Unintended Thought. New York: Guilford, 1989. p. 253-283.

FIÚZA, A. L. C. Mulheres nas políticas de desenvolvimento sustentável. In:__. BRUSCHINI, C.; PINTO, C. R. (Org.). Tempos e lugares de gênero. São Paulo: FCC/Editora 34, 2001. p. 87-118. 
FONSECA, T. M. G. Utilizando Bourdieu para uma análise das formas sustentáveis de ser homem e mulher. In: STREY, M. N. et al. (Org.). Construções e perspectivas em gênero. São Leopoldo: Unisinos, 2000. p. 19-32.

FORMIGA, N. S. As bases normativas do sexismo ambivalente: a sutileza do preconceito frente às mulheres à luz dos valores humanos básicos. In: . MARCUS E. O. et al. (Org.). Estereótipos, preconceitos e discriminação: perspectivas teóricas e metodológicas. Salvador: UFBA, 2004. p. 259-276.

FORMIGA, N. S.; QUEIROGA, F.; GOUVEIA, V. V. Indicadores do bom estudante: sua explicação a partir dos valores humanos. Aletheia, Rio Grande do Sul, v. 13, p. 63-73, 2001.

FORMIGA, N. S.; GOUVEIA, V. V.; SANTOS, M. N. Inventário de sexismo ambivalente: sua adaptação e relação com o gênero. Psicologia em Estudo, Paraná, v. 7, n. 1, p. 105-111, 2002.

FORMIGA, N. S. et al. Flagrando o preconceito: Uma análise descritiva das atitudes preconceituosas frente aos negros, mulheres e homossexuais. In:

In: REUNIÃO ANUAL DA SOCIEDADE BRASILEIRA DE PSICOLOGIA: Formação do psicólogo brasileiro: História de desafios e conquistas, 34., 2004, Ribeirão Preto - SP. Anais... Ribeirão Preto: [s.n.], 2004.

FRAISSE, G. Da destinação ao destino: história filosófica da diferença entre os sexos. In: DUBY, G.; PERROT., M. (Org.). História das mulheres no Occidente: o século XIX. Porto: Afrontamento, 1991. p. 59-96.

GLICK, P.; FISKE, S. T. The ambivalent sexism inventoy: differentiating hostile and benevolent sexism. Journal of Personality and Social Psychology, Washington, v. 70, p. 491-521, 1998.

GÓMEZ, A.; HUICI, C. Valores y reducción del prejuicio. In: ROS, M.; GOUVEIA, V. (Coord.). Psicología social de los valores humanos: avances teóricos, metodológicos y aplicados. Madrid: Alianza, 1999. p. 219-237.

GOUVEIA, V. V.; SILVA, R.; BELO, R. P. Sexismo ambivalente e valores humanos. In: CONGRESSO NORTE-NORDESTE DE PSICOLOGIA: Construindo a Psicologia Brasileira: desafios da ciência e prática psicológica, 3., 2003. Anais... João Pessoa: UFPB, 2003. p. 242-243.

GOUVEIA, V. V.; QUEIROGA, F. Desejabilidade social e prioridades valorativas: estilo de resposta ou traço de personalidade? Relatório de pesquisa. João Pessoa: PIBIC/CNPq/UFPB, 2001. 
GOUVEIA, V. V. La naturaleza de los valores descriptores del individualismo e del colectivismo: una comparación intra e intercultural. Tese (Doutorado)--Universidade Complutense de Madri, Espanha, 1998.

GUSMÃO, E. E. S. et al. Interdependência social e orientações valorativas em adolescentes. Revista Psico, Rio Grande do Sul, v. 32, p. 23-37, 2001

INGLEHART, R. El cambio cultural en las sociedades industriales avanzadas. Madri: Centro de Investigaciones Sociológicas / Siglo XXI, 1991.

KLINEBERG, O. Psicología Social. México: Fondo de Cultura Económica, 1974.

LIMA, M. E. O impacto do igualitarismo e da meritrocacia individualista no preconceito automático contra os negros. In: CONGRESSO NORTE-NORDESTE DE PSICOLOGIA: Construindo a Psicologia Brasileira: desafios da ciência e prática psicológica, 3., 2003. Anais... João Pessoa: UFPB, 2003a. p. 237.

. Cor da pele e sucesso social: efeitos do branqueamento nas novas formas de expressão do racismo. In: CONGRESSO NORTE-NORDESTE DE PSICOLOGIA: Construindo a Psicologia Brasileira: desafios da ciência e prática psicológica, 3., 2003. Anais... João Pessoa: UFPB, 2003b. p. 240.

LIMA, M. E. O.; VALA, J. Serão os estereótipos e o preconceito inevitáveis? O mostro da automaticidade. In: LIMA, M. E. O.; PERREIRA, M. E. (Org.). Estereótipos, preconceitos ediscriminação: perspectivas teóricas e metodológicas. Salvador: UFBA, 2004. p. 41-68.

MAIA, L. M. V. Prioridades valorativas e desenvolvimento moral: considerações acerca de uma teoria dos valores humanos. 2000. Dissertação (Mestrado)-Universidade Federal da Paraíba, João Pessoa, 2000.

MLADINIC, A. et al. Sexismo ambivalente en estudiantes universitarios chilenos: teoría, medición y diferencias del género. Revista de Psicología Social y Personalidad, México, v.14, p. 1-14, 1998.

MONTE, D. F. C.; FORMIGA, N. S. Entre o pensar e agir: a percepção das pessoas a respeito do negro em nossa sociedade. Doxa, Minas Gerais, v. 6, n. 1-2, p. $7-16,2000$.

MONTE, D. F. C. Aspectos do preconceito étnico em relação ao negro: um estudo empírico no setor supermercadista de João Pessoa - PB. Dissertação (Mestrado)-Universidade Federal da Paraíba, João Pessoa, 2001. 
MUNNÉ, F. M. Prejuicios, estereotipos y grupos sociales. In: MORALES J. F.; MOYA, M. C. (Org.). Tratado de Psicologia Social: processos básicos. Madrid: Síntesis, 1996. p. 315-363.

MYERS, D. G. Preconceito: o ódio ao próximo. In: . Psicologia Social. Rio de Janeiro: LTC, 1999. p.181-206.

OLIVEIRA, D. D. et al. A cor do medo. Brasília: UNB/UFC, 1998.

PÁEZ, D.; TORRES, B.; ECHEBARRÍA, A. Esquema de si, representación social y estereotipo sexual. In: MUSITU, G. (Org.). Procesos psicosociales básicos. Barcelona: PPU, 1990. p. 229-234.

PETTIGREW, T. F.; MEERTENS, R. W. Subtle and blatant prejudice in Western Europe. European Journal of Social Psychology, v. 25, p. 57-75, 1995.

PRINGLE, R. Feminist theory and the world of the social. Current Sociology, V. 45, p. 75-89, 1997.

RODRIGUES, A. Preconceito, estereótipos e discriminação In: Psicologia Social. Petrópolis: Vozes, 2001. p. 147-176.

ROKEACH, M. The nature of human values. New York: Free Press. 1973.

. (Ed.). Introduction. In: Understanding human values: individual and

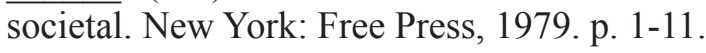

RONEN, S. An underlying structure of motivational need taxonomies: a crosscultural confirmation. In: . TRIANDIS, H. C.; DUNNETTE, M. D.; HOUGH, L. M. (Ed.). Handbook of industrial and organizational psychology. Palo Alto, CA: Consulting Psychologists Press, 1994. v. 4, p. 241-269.

SCHWARTZ, S. H.; BILSKY, W. Toward an universal psychological structure of human values. Journal of Personality and Social Psychology, v. 53, p. 550-562, 1987.

SCHWARTZ, S. H. Universals in the context and structure of values: theoretical advances and empirical tests in 20 countries. In: ZANNA M. (Ed.). Advances in experimental social psychology. Orlando, FL: Academic Press, 1992. v. 25 , p. 1-65.

. Are there universal aspects in the structure and contents of human values?

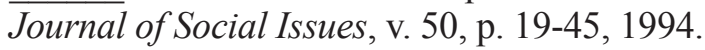


SIANO, J. A. Constituição da Republica Federativa do Brasil. São Paulo: Rideel. 2000 .

SWIM, J. K.; AIKIN, K. J.; HALL, W. S.; HUNTER, B. A. Sexism and racism: old-fashioned and modern prejudices. Journal of Personality and Social Psychology, v. 68, p. 199-214, 1995.

TAMAYO, A. Influência do sexo e da idade sobre o sistema de valores. Arquivos Brasileiros de Psicologia, v. 40, p. 91-104, 1998.

TORRES, R. R. La influencia de la inducción afectiva sobre el prejuicio racial. Revista de Psicología Social, São Paulo, v. 2, n. 13, p. 279-289, 1998.

TOUGAS, F. et al. Neosexism: Plus ça change, Plus c'est pareil. Personality and Social Psychology Behavior, v. 21, n .8, p. 842-849, 1995.

VASCONCELOS, T. C. Atitudes preconceituosas em relação aos negros: uma análise a partir das prioridades valorativas. 2001. Monografia (Graduação)Universidade Federal da Paraíba, João Pessoa, 2001.

Recebido em: março de 2005 Aceito em: fevereiro de 2006 